\title{
Desafios e possibilidades da atividade mediadora do bibliotecário na normalização de trabalhos acadêmicos: 0 uso do LaTeX
}

\author{
Challenges and possibilities of the librarian's mediation role to standardize academic works: \\ using the LaTeX
}

Francisco Edvander Pires Santos Mestrando em Ciência da Informação pela Universidade Federal do Ceará - UFC. Bibliotecário da Universidade Federal do Ceará - UFC.

E-mail: edvanderpires@gmail.com

Juliana Soares Lima
Mestranda em Ciência da Informação pela Universidade Federal do Ceará - UFC.
Bibliotecária da Universidade Federal do Ceará - UFC.
E-mail: julia10br@ gmail.com
Ednardo Moreira Rodrigues
Eoutorando em Engenharia Elétrica pela Universidade Federal do Ceará - UFC.
E-mail: ednardorodrigues@ @ee.ufc.br
Izabel Lima dos Santos
Especialista em Gestão Pública.
Bibliotecária da Universidade Federal do Ceará - UFC.
E-mail: zbel.lima@ gmail.com
Kalline Yasmin Soares Feitosa
Especialista em Gestão de Documentos e Informações.
Bibliotecária da Universidade Federal do Ceará - UFC.
E-mail: kallineyasmin@ gmail.com

\section{Resumo}

O artigo aborda a atuação do bibliotecário frente às novas demandas dos usuários, para as quais se faz necessário conhecer as ferramentas disponíveis, dentre elas o LaTeX. Tem por objetivo apresentar e incentivar o uso do LaTeX por bibliotecários e usuários de bibliotecas universitárias, com a finalidade de compreendê-lo em sua estrutura e enquanto recurso utilizado pela comunidade na produção e normalização de trabalhos acadêmicos. Trata-se de uma pesquisa bibliográfica, de natureza aplicada, caracterizada também como pesquisa-ação, subsidiada pelas seguintes estratégias de coleta de dados: a observação da estrutura de teses e dissertações da área de Física e a realização de testes em softwares de edição em LaTeX. Discorre acerca da importância da participação do bibliotecário na normalização de trabalhos acadêmicos por meio do uso do $L a T e X$, ao explanar sucintamente as suas funcionalidades na edição de textos complexos e na definição de comandos para citação e referências bibliográficas, com uso do formato BibTeX e do gerenciador de referências JabRef. Apresenta a proposta de um template desenvolvido na plataforma ShareLaTeX, ferramenta online disponível para a edição compartilhada, estruturado em conformidade com as normas da Associação Brasileira de Normas Técnicas (ABNT). Destaca, por fim, ser essencial o bibliotecário manter-se atento às novas ferramentas de normalização bibliográfica, sendo apresentada a ferramenta LaTeX como mais um recurso disponível para as bibliotecas universitárias, exigindo do bibliotecário o compromisso em compreender, avaliar e aperfeiçoar as funcionalidades de acordo com as especificidades de cada área do conhecimento.

Palavras-chave: Normalização de trabalhos acadêmicos. Editoração. Estilos bibliográficos. Gerenciadores de referências. Formato BibTeX. LaTeX (programas de computador). 


\begin{abstract}
This study presents the librarian's role in front of new users' demand for which it has made necessary to know tools that have been available, as the $L a T e X$. In this respect, it aims to introduce and motivate librarians and students to use the LaTeX by understanding it under its structure and as a resource that has been used by the users of academic libraries in their works. So it was made a bibliographic research to apply the concepts through an action research, which was based on two strategies to collect data: from the observation of the structure of theses and dissertations on Physics and from tests that were made by using some LaTeX editors. This paper also discusses the importance of standardizing academic works by using the LaTeX and encouraging librarians to carry it out. Then, the main functions of the LaTeX are presented as a tool developed to edit complex texts and to define commands for citations and bibliographical references through the BibTeX format and the reference manager called JabRef. Thus, this study presents a proposal of template which was structured on ShareLaTeX, which is available online to edit and to share complex text. The template was developed according to the Brazilian standardization, which is managed by the Associação Brasileira de Normas Técnicas (ABNT), focusing on contributing to format technical and scientific works. Finally, it points out the importance of librarians to be prepared to attend new demand from users, mainly referring to the new ways to standardize academic works, taking the LaTeX as an example to be understood by librarians and to be used in academic libraries, according to specificities of each area of knowledge.
\end{abstract}

Keywords: Standardization of academic works. Text editor. Bibliographic styles. Reference managers. BibTeX format. LaTeX (software).

\title{
1. Introdução
}

A atuação do bibliotecário deve satisfazer plenamente a demanda por informação apresentada pela comunidade usuária da biblioteca, e uma dessas demandas envolve, no cenário acadêmico, o conhecimento das ferramentas e dos recursos informacionais disponíveis, para que se cumpra efetivamente a missão do serviço de referência. No entanto, nem sempre essas ferramentas são consideradas de fácil compreensão para o bibliotecário, como é o caso do LaTeX. Nesse sentido, o objetivo deste estudo é apresentar e incentivar o uso dessa ferramenta na produção, editoração e normalização de trabalhos acadêmicos por bibliotecários e usuários, com base na estruturação de um template de acordo com as normas da Associação Brasileira de Normas Técnicas (ABNT) e tendo em vista a possibilidade de discutir em treinamentos oferecidos por bibliotecas universitárias alguns dos aspectos do LaTeX que concernem à estruturação de citações e referências bibliográficas.

No contexto da produção e disseminação de trabalhos de conclusão de curso em meio eletrônico, a exemplo de teses e dissertações, dispensando, em alguns casos, a versão impressa do documento, há recursos, muitas vezes até exigidos pelos próprios usuários, que têm sido primordiais à formatação dos trabalhos acadêmicos, e com isso passam a gerar uma demanda específica para a biblioteca universitária. São alguns exemplos dessa exigência: a inclusão de 
links ativos, na relação sumário-seções ou citações-referências, por exemplo; a definição de remissivas no decorrer do próprio texto, de um capítulo para outro, de uma parte para outra, de um trecho para um anexo ou apêndice, com acesso à informação ao clicar no mouse uma única vez; a existência de referências cruzadas ${ }^{1}$ no decorrer do texto, as quais servem de remissiva na medida em que, com um clique sobre a menção da fonte, o leitor é conduzido à referência ao final do trabalho; a alta qualidade na estrutura do documento, ao serem aliados formatação e conteúdo; a estruturação de fórmulas e equações complexas, dentre outras necessidades da escrita científica.

A partir dessas observações, constatamos que o LaTeX é uma ferramenta de edição de textos que auxilia e que supre satisfatoriamente a essas necessidades de formatação textual, principalmente do ponto de vista das Ciências Exatas e Engenharias. Sabemos que as publicações dessas áreas vêm repletas de cálculos, equações, fórmulas e patentes, e que o avanço da pesquisa científica se dá em larga escala; portanto, entender os recursos e as ferramentas utilizadas pelos pesquisadores em suas produções textuais é um diferencial na atuação do bibliotecário que atender diretamente a essa comunidade.

Foi essa constatação que motivou o desenvolvimento deste trabalho, por meio da análise, ainda que sucinta, das funcionalidades do LaTeX. Também serviu de motivação o questionamento de um dos usuários na ocasião de treinamento sobre normalização de trabalhos acadêmicos e gerenciadores de referências, e ao qual não soubemos de que maneira orientar para a solução da questão apresentada, especificamente sobre a estruturação de trabalhos com a linguagem do LaTeX. Assim, foi ratificada a necessidade de o bibliotecário estar envolvido com mais essa ferramenta amplamente utilizada na produção de trabalhos técnico-científicos. Partindo, então, da composição de uma equipe multidisciplinar, de experiências adquiridas na área de Física, de treinamentos para a comunidade das áreas de Ciências Sociais Aplicadas, de reuniões de planejamento com bibliotecários das Ciências Humanas e de parceria firmada com estudantes de pós-graduação da Engenharia Elétrica, foi possível estruturar um template e um tutorial que possibilitaram maior contato com o LaTeX e com as suas funcionalidades.

Apesar de haver templates em LaTeX disponíveis na Internet, que mantêm em sua estrutura um padrão próprio adotado, faz-se necessário considerar as particularidades de cada

\footnotetext{
${ }^{1}$ A referência cruzada cria uma espécie de hyperlink ativo numa parte selecionada do texto, que remete o leitor a uma figura, tabela, gráfico, equação, anexo, apêndice ou mesmo a uma referência ao final do trabalho. Dessa forma, o leitor salta para o item referido no mesmo documento (OLIVEIRA, 2007).
} 
instituição, curso, programa de pós-graduação, revista científica e editora, em nível nacional ou internacional, pois é certo que nem sempre os autores, pesquisadores e editores seguirão à risca as orientações respaldadas pela $\mathrm{ABNT}$, no que se refere à normalização de trabalhos técnicocientíficos. Essa realidade foi constatada com base no atendimento a usuários da área de Física e na observação da estrutura das teses e dissertações submetidas em Repositório Institucional. Mesmo com os treinamentos de normalização oferecidos pela biblioteca universitária, a comunidade das Ciências Exatas quase sempre opta pelo estilo bibliográfico e de citação

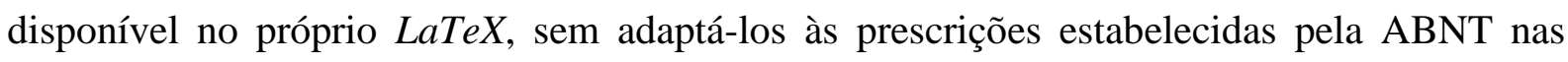
normas de documentação, uma cultura que precisa ser entendida pelo bibliotecário e incorporada ao seu cotidiano profissional, pois o formato de normalização em LaTeX é universal e tradicionalmente consolidado nas universidades.

A persistência dessa conduta por parte dos usuários, embora existam manuais de normalização e realização periódica de treinamentos, leva-nos a refletir sobre as causas desse comportamento. Uma delas é a falta de familiaridade dos alunos com o uso das normas, tendo em vista que muitos deles não exercem o que aprendem nos treinamentos ou participam dessas atividades na iminência de entrega dos trabalhos e, assim, acabam por sentir maior dificuldade em aplicá-las. Essa dificuldade faz com que os templates em LaTeX sejam vistos como uma solução simples para as dúvidas com normalização. Uma vez que a maioria dos alunos se exime da necessária tarefa de conferir se o template que pretende utilizar foi construído com base na ABNT, ou em releituras dessa norma, essa prática acaba por contribuir para as inconsistências na normalização dos trabalhos, ao invés de resolvê-las. Foi sob essa perspectiva que surgiu a proposta de estruturação de um template seguindo o estilo ABNT, com a finalidade de disponibilizar para a comunidade acadêmica uma plataforma de edição em LaTeX compatível com as diretrizes estabelecidas nas normas.

A própria $\mathrm{ABNT}$ possui uma formatação em $\operatorname{LaTeX}$, que é o pacote $\mathrm{ABNTeX2}$ (ARAUJO, 2016a, 2016b, 2016c). Quando os alunos utilizam esse pacote, eles acreditam que já estão cumprindo as prescrições trazidas pelas normas da ABNT; contudo, o pacote não é desprovido de erros, quanto ao que a supervisão de um bibliotecário é primordial. Portanto, um modelo elaborado pela biblioteca universitária já elimina grande parte desses erros. 


\section{Percurso metodológico}

Para fins deste estudo, a intenção não é ater-se às características de programação do LaTeX, mas sim em suas particularidades no que se refere à formatação do documento, mais especificamente nos casos de trabalhos acadêmicos. Recorremos, então, à pesquisa bibliográfica, contemplando a normalização de trabalhos acadêmicos e as funcionalidades do LaTeX. Além disso, consideramos esta pesquisa como sendo de natureza aplicada, que, na definição de Appolinário (2009, p. 152), é aquela "realizada com o objetivo de resolver problemas ou necessidades concretas e imediatas [...] Contrapõe-se à pesquisa básica".

$\mathrm{Na}$ etapa de planejamento desta pesquisa, entre os meses de maio de 2014 a dezembro de 2015, foram feitas observações da estrutura das teses e dissertações publicadas pelo Programa de Pós-Graduação em Física da Universidade Federal do Ceará (UFC), as quais são submetidas ao Repositório Institucional. A partir da análise da normalização dessas publicações, que nem sempre estavam em conformidade com as normas da ABNT, foram feitas anotações que conduziram ao contato com o $\mathrm{LaTeX}$. Apesar das referidas teses e dissertações nem sempre condizerem com as normas da ABNT, a sua estrutura segue o próprio estilo bibliográfico e de citações do LaTeX, assim como o tipo e tamanho da fonte, formatação, definição das margens etc., variando de acordo com o formato BibTeX, com o template usado pelo professor orientador ou com o template da revista científica na qual o estudo é publicado a posteriori.

Conversas informais com alguns dos usuários da biblioteca também foram essenciais para o entendimento do LaTeX, na medida em que esses mesmos usuários que tinham domínio sobre essa ferramenta compartilhavam os seus conhecimentos com o bibliotecário responsável pelo serviço de referência. Além disso, mantivemos contato com o Laboratório de Estatística e Matemática Aplicada da UFC, e houve conversas informais com dois professores acerca do uso do LaTeX nas Ciências Exatas. Foram, então, esclarecidas algumas dúvidas e ratificado o argumento, com base nas opiniões dos professores, de que uma padronização no uso do LaTeX, visando à normalização, é tarefa bastante difícil de ser alcançada, pois cada curso ou programa de pós-graduação tende a seguir um template próprio.

Passando para a etapa de testes, constatamos que existem vários softwares editores de LaTeX. Conforme sugerido por Lopez e Silva (2013, p. 9), escolhemos, inicialmente, o software 
LyX com a finalidade de trabalhar na estruturação de um template, pois os referidos autores o destacam como o editor mais recomendado para os iniciantes em LaTeX. No entanto, não obtivemos êxito nos testes devido ao pouco conhecimento sobre a ferramenta. Em seguida, foram realizados testes com o TeXmaker, pois, segundo as observações, este foi o software mais utilizado pela comunidade usuária atendida pela biblioteca da área de Física. Na instalação do editor TeXmaker, em simultâneo, foi necessária a instalação do $M i K T e X$, compilador que converte o trabalho da linguagem em LaTeX para o formato de saída, normalmente PDF. A partir das orientações recebidas por parte de alguns usuários, foi possível compreender a estrutura dessa complexa linguagem e delinear estratégias para propor e disponibilizar um template no site da biblioteca.

Contudo, na ocasião de um dos treinamentos de normalização de trabalhos acadêmicos ministrados na biblioteca da área de Ciências Sociais Aplicadas, houve o feedback por parte de dois estudantes do curso de Engenharia Elétrica, os quais se dispuseram a contribuir com a biblioteca universitária na estruturação de um template na plataforma ShareLaTeX, em conformidade com as normas da ABNT. O trabalho foi realizado entre os meses de julho a setembro de 2016, com o objetivo de disponibilizar o template no site da biblioteca juntamente com um tutorial elaborado pelos bibliotecários conforme as orientações recebidas em reuniões com os estudantes.

Dessa forma, optamos pela pesquisa-ação como método para o desenvolvimento deste estudo. Appolinário (2009, p. 151-152) define pesquisa-ação como sendo uma "modalidade de pesquisa aplicada cujo objetivo básico é o de resolver, através da ação, algum problema coletivo no qual os pesquisadores e sujeitos da pesquisa estejam envolvidos de modo cooperativo e participativo [...]" Para Elliot (2000, p. 17), a pesquisa-ação é um processo que se modifica continuamente em espirais de reflexão e ação. Ilustramos, na figura 1, o ciclo que caracteriza essas espirais: 


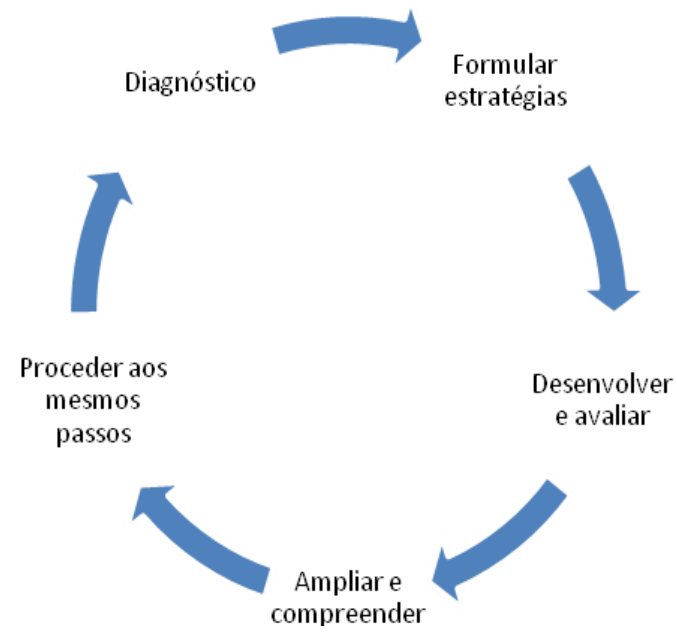

Figura 1 - Espirais da pesquisa-ação.

Fonte: Baseado em Elliot (2000).

Aplicando cada uma dessas espirais a esta pesquisa, o diagnóstico se deu quando foi identificada uma necessidade de informação que contemplava aspectos relativos à normalização de trabalhos acadêmicos. Formulamos, então, estratégias para compreender a estrutura do LaTeX e envolver os bibliotecários do serviço de referência de três bibliotecas específicas: Biblioteca do Curso de Física, Biblioteca de Ciências Humanas e Biblioteca da Faculdade de Economia, Administração, Atuária e Contabilidade da UFC. Posteriormente, um template foi desenvolvido no ShareLaTeX a partir da adequação de código-fonte de templates disponíveis em repositórios na Internet.

A avaliação tem sido feita continuamente baseada na divulgação e no uso desse produto no site da biblioteca. As etapas seguintes (ampliar e compreender e proceder aos mesmos passos) serão delineadas em ações ou pesquisas futuras, a partir da atuação dos bibliotecários e das parcerias firmadas que serão mantidas para o aperfeiçoamento e a contínua compreensão do LaTeX. De antemão, ressaltamos que o template tem sido frequentemente atualizado, e essa é uma das maiores vantagens do ShareLaTeX. Uma das estratégias para essa permanente avaliação é o acompanhamento das defesas de teses e dissertações no Programa de PósGraduação em Engenharia Elétrica da UFC, onde os desenvolvedores do template atentam para as considerações das bancas examinadoras no sentido de observar se os usuários estão interpretando erroneamente algum aspecto da estrutura do template. Desse modo, as alterações são feitas em tempo real e, no caso de dúvidas, mediante a consulta aos bibliotecários da instituição. 


\section{O bibliotecário e a normalização de trabalhos acadêmicos}

São muitos os desafios para a atualização e educação continuada dos bibliotecários, principalmente por parte dos bibliotecários do serviço de referência, afinal, são estes os responsáveis pela orientação e capacitação de seus usuários. Para Silva (2005, p. 33), o bibliotecário de referência é “o profissional que mantém o contato mais próximo dos usuários de uma unidade de informação. Através dele, é criada uma interface direta entre a informação e o usuário, sendo este o momento em que exerce especificamente o serviço de referência". Além disso, o referido autor também ressalta a dificuldade dos usuários em utilizar os recursos disponíveis de maneira efetiva, no sentido de que "Torna-se cada vez mais difícil divulgar quais recursos estão disponíveis, pois as especificidades de acesso mudam ano a ano e os usuários prestam pouca atenção a essas mudanças" (SILVA, 2005, p. 34). Assim, cabe ao bibliotecário do serviço de referência conduzir cada usuário a cada ferramenta ou recurso disponível que atende à sua necessidade de informação.

Entendemos que o processo de formatação e normalização de trabalhos acadêmicos no LaTeX é um dos muitos recursos disponíveis com os quais o usuário e os bibliotecários têm acesso no ambiente universitário. É um recurso que deve ser disponibilizado e divulgado pelos bibliotecários como uma ferramenta agregadora à produção e normalização de textos acadêmicos, pois favorece a economia de tempo na edição do texto, principalmente devido à existência de templates e de repositórios de citações disponíveis na Web. Estilos bibliográficos para trabalhos acadêmicos, como as normas da ABNT, são importantes e devem ser utilizados visando à padronização e uniformização da estrutura do documento. Contudo, é possível perceber que cada área possui as suas especificidades, o que se reflete no uso das normas, no conteúdo do trabalho e nas ferramentas que serão utilizadas na composição do texto, e o bibliotecário do serviço de referência precisa atentar para essas características.

Concordamos com Martins Filho (2016, p. 658) quando afirma que: "Não há um consenso acerca da normalização de bibliografias". Cada área tem as suas especificidades com relação ao formato, estilo de escrita e detalhes relacionados intrinsecamente à área de atuação. Exemplo disso são as normas de Vancouver: é uma norma própria para a Medicina, bastante utilizada em diversos periódicos da área de saúde. As normas foram criadas por um comitê de editores de revistas científicas na área de Medicina e, assim, foram estabelecidas regras próprias e com características mais diretamente ligadas à sua área do conhecimento e campo de atuação

InCID: R. Ci. Inf. e Doc., Ribeirão Preto, v. 9, n. 1, p. 25-51, mar./ago. 2018. 
(INTERNATIONAL COMMITTEE OF MEDICAL JOURNAL EDITORS, online). Não é à toa que essas normas versam de forma objetiva e direta sobre a preparação dos manuscritos, o formato que deve ter o documento, margens, espaçamento e estrutura, e tratam de forma mais ampla sobre outros aspectos, como a ordem de autoria, questões editoriais, funções e responsabilidades, conflitos de interesses, regras para registro de ensaios clínicos, parecer de comitê de ética etc. Outro exemplo são as normas da APA (AMERICAN PSYCHOLOGICAL ASSOCIATION, 2012), criadas por um grupo de editores de periódicos das áreas de Antropologia e Psicologia, que estabeleceram procedimentos para preparação e formatação dos artigos dessas áreas. Assim como as normas de Vancouver, as normas da APA seguem tratando de ética em publicações científicas, estilo de escrita próprio da área, entre outras abordagens.

Enquanto isso, as normas da ABNT, em nível nacional, são mais direcionadas ao formato e à apresentação final dos documentos, não tratando de referências relacionadas a uma área específica do conhecimento. Já o estilo bibliográfico do LaTeX é consolidado internacionalmente pelas Ciências Exatas segundo o formato BibTeX, e por esse motivo é quase impossível romper com a cultura estabelecida pelos pesquisadores no que se refere ao uso dos editores LaTeX. Apesar disso, consideramos que a estruturação de templates no estilo ABNT favorece a padronização tendo em vista as publicações para as instituições brasileiras, dentre universidades e periódicos científicos.

Sendo o LaTeX uma linguagem de programação para editoração, ele permite criar documentos escritos com resultados satisfatórios de layout e apresentação. Diferenciando-se do Microsoft Word, por exemplo, no qual o usuário edita diretamente o documento final, o editor em LaTeX gera um arquivo que será compilado posteriormente; assim, é possível ter um controle sobre o layout do manuscrito. Além disso, o código de um documento já estruturado pode ser reutilizado no LaTeX para criar novos documentos, e talvez seja por esse motivo, e também por sua versatilidade e por ser uma linguagem universal e em código aberto, que o LaTeX tem sido utilizado por diversas áreas, pois, dependendo da norma a ser aplicada e seguida, seja ABNT, APA, Vancouver ou qualquer outra, todas as possibilidades de aplicação e ajustes no layout são possíveis.

Diante disso, é preciso atentar para a necessidade de padronização dos trabalhos acadêmicos e adequação às normas vigentes, respeitando as especificidades de cada comunidade de usuários das bibliotecas. Para tanto, o bibliotecário exerce o seu papel de 
mediador ao conduzir o usuário na melhor maneira de estruturar o documento a ser disponibilizado para a comunidade e, ainda, ao orientá-lo quanto ao uso das ferramentas e dos recursos disponíveis para produção, formatação e normalização dos trabalhos. Visando tratar dessa relação mediadora entre bibliotecário e normalização de trabalhos acadêmicos, destacaremos o uso e as funcionalidades do LaTeX, uma ferramenta de edição de textos em alta qualidade que contempla as principais necessidades de produção técnico-científica das Ciências Exatas e de áreas afins.

\title{
4. O LaTeX e a normalização de trabalhos acadêmicos
}

O LaTeX é codificado por meio de uma linguagem de programação, livre e tem sido utilizado especialmente para a estruturação de textos matemáticos (CLARK, 1992; MITTELBACH et al., 2004). Surgiu a partir do programa $T e X$, conforme explicado por Souto ([200-], p. 1-2):

\begin{abstract}
TEX (pode-se escrever "TeX") é um programa de computador de Donald E. Knuth. Está orientado à composição e impressão de textos e fórmulas matemáticas. A pedido da AMS [American Mathematical Society], Donald Knuth desenvolveu uma linguagem de computador para desenvolver textos com muitas equações. $\mathrm{O}$ trabalho se estendeu de 1977 a 1986, quando TEX foi colocado de maneira gratuita para ser usado [...] Pode-se considerar TEX como sendo um compilador para textos científicos, que produz textos de alta qualidade de composição. Como todo compilador, a sua aprendizagem não é para qualquer usuário de computador. Porém, quase simultaneamente foi desenvolvido o LATEX [também se pode escrever "LaTeX"] por Leslie Lamport, que criou um conjunto de macros para simplificar o uso da linguagem TEX. Esses macros definem tipos de documentos, tais como cartas, artigos, livros, reportes, assim como macros para definir ambientes para equações matemáticas, entre outros.
\end{abstract}

Existem diversos softwares disponíveis na Internet a partir dos quais se podem explorar as funcionalidades do LaTeX. Para tanto, Lopez e Silva (2013) orientam os iniciantes no estudo do LaTeX sobre quais softwares utilizar num primeiro contato com essa linguagem, levando em consideração os principais sistemas operacionais disponíveis no mercado, bem como a comparação do LaTeX com os principais editores de textos utilizados na produção de trabalhos acadêmicos:

Em Windows, dos editores que são software livre, são mais indicados o TeXworks, Texmaker e TeXnicCenter. Para Linux tem-se o TeXworks, Texmaker, Kile, LyX, além de outros editores tradicionais que apresentam facilidades para editar arquivos em LATEX [...] [Há também o TeXstudio]. O LyX permite editar arquivos em LATEX usando uma interface do estilo do Microsoft Office ou do LibreOffice. Este programa pode ser uma boa opção para quem está começando a utilizar o LATEX. A

InCID: R. Ci. Inf. e Doc., Ribeirão Preto, v. 9, n. 1, p. 25-51, mar./ago. 2018. 
versão para Linux é bastante estável e está em constante desenvolvimento. No final de 2012 foi lançada uma versão atualizada para Windows. Em uma das opções de instalação do Windows, o LyX vem junto com a distribuição MiKTeX, o que pode ser uma boa escolha para os usuários que querem se iniciar no LaTeX de uma forma rápida utilizando interface semelhante aos editores do tipo Office sem se preocupar com a instalação de uma distribuição de LATEX [...] (LOPEZ; SILVA, 2013, p. 9).

Contudo, o editor que embasou este artigo foi o ShareLaTeX, disponível online para a edição compartilhada e que tem se integrado à plataforma Overleaf. O contato com o ShareLaTeX se deu a partir de um feedback recebido por estudantes de pós-graduação em Engenharia Elétrica na ocasião de treinamentos de normalização. Ainda sobre softwares, Neves (2007, p. 4) especifica o que é feito num editor e num compilador em LaTeX, diferenciando-os, basicamente, quanto à estruturação do documento a partir de comandos (função do editor) e à conversão do documento para PDF (função do compilador).

Apesar de haver softwares em língua portuguesa, o idioma talvez seja a primeira dificuldade quando o bibliotecário se depara com o LaTeX, pois grande parte dos manuais, do material bibliográfico e, principalmente, dos comandos encontra-se em língua inglesa. Outra dificuldade a ser enfrentada é quanto à linguagem de programação, cujo embasamento norteia a estrutura do LaTeX e caracteriza o pacote em seu todo. Ainda há a questão de entender o significado de cada um dos comandos e códigos, tendo em vista a formatação do trabalho, bem como a sua normalização, mencionando, dentre outras funcionalidades, as fontes bibliográficas utilizadas no decorrer do texto.

Para além da escolha de um software, Cherem (2015) discorre acerca das características tipográficas, de diagramação e editoração do documento em LaTeX, considerando aspectos de leitura, produção textual e estruturação do formato visual. Na perspectiva da escrita versus formatação, Cherem (2015, p. 230-231) afirma que:

O propósito do LaTeX é proporcionar aos autores a melhor qualidade tipográfica possível, com um mínimo de esforço ou de conhecimento técnico [...] Em outras palavras, uma vez já definido o aspecto visual da publicação - seja por um designer, um programador, ou uma combinação de ambos [mais especificamente por meio de um template] - o processo de edição do texto suprime a figura do tipógrafo e do designer, que serão cumpridas pelo programa (LaTeX). Essa separação entre forma e conteúdo é especialmente útil ao concentrar atenção do redator ou autor no conteúdo do texto, e não em sua aparência final [quando da normalização segundo as normas da ABNT, por exemplo]. O próprio processo de trabalho para produção de um texto utilizando LaTeX impõe uma separação visual entre o arquivo-fonte e seu resultado imprimível. O usuário deve empregar comandos que explicitem a estruturação lógica do texto (partes, capítulos, seções etc.). 
Nesse sentido, há a preocupação com a estética do documento, com aquilo que o leitor visualizará (NEVES, 2007). No caso das Ciências Exatas, a necessidade em disponibilizar cálculos e fórmulas complexas faz com que o fator estética seja crucial na apresentação do trabalho, o que é ratificado por Neves (2007, p. 2-3) e corroborado no atendimento a usuários da área de Física, comunidade a partir da qual este artigo começou a ser delineado. Além disso, existem diversos templates disponíveis na Internet, cuja estrutura varia de acordo com cada instituição e com a normalização adotada como padrão. Assim, periódicos e instituições das áreas de Física, Estatística, Matemática, Computação e Engenharias possuem templates próprios disponibilizados para o autor, bem como há bibliotecas universitárias que têm se envolvido nessa realidade a fim de adequar as normas vigentes à estruturação de templates. Nas Ciências Humanas e na editoração comercial, também há registro de trabalhos com o LaTeX (CHEREM, 2015, p. 243).

Lopez e Silva (2013) destacam os principais comandos que fazem parte da estrutura do LaTeX: \documentclass (define a classe de documento - artigo, livro, tese etc.); \chapter (entra com o título de capítulo ou seção primária); Isection (entra com o título de seção secundária) ${ }^{2}$; Isubsection (entra com o título de seção terciária); \cite (introduz uma citação); e Vbibliography (cria a seção de referências ao final do trabalho). Para estruturar uma equação, basta inseri-la entre cifrões simples ( $\$$ inserir equação aqui \$), duplos (\$ inserir equação aqui \$ \$) ou proceder da seguinte forma: \begin\{equation\} inserir equação aqui \end\{equation\}. }

No que se refere à formatação e normalização do trabalho, o LaTeX permite a inserção de fórmulas, equações matemáticas e códigos de alta complexidade, além de possibilitar as referências cruzadas, remissivas, índices, imagens em diversos formatos, dentre outros recursos. A conversão do arquivo em PDF gera automaticamente os marcadores (bookmarks), que correspondem a cada capítulo ou seção que compõe o documento. Também é possível visualizar hyperlinks na estrutura do sumário, que remetem diretamente a qualquer uma das seções do trabalho com apenas um clique. Da mesma forma, é possível clicar sobre a menção da fonte numa determinada citação e ser remetido diretamente para a referência ao final do trabalho, ou seja, uma função de referências cruzadas.

\footnotetext{
${ }^{2}$ Em LaTeX, há a distinção entre capítulos e seções. Inter-relacionando com os conceitos apresentados pelas normas da ABNT, os “capítulos” são as seções primárias, e as "seções” seguem a estrutura das seções secundárias.
} 
Exemplificaremos os casos de referências cruzadas, utilizadas exaustivamente nos trabalhos em LaTeX, com base em Kottwitz (2011), que apresenta os comandos usados para se referir a um ponto específico do texto, bem como de que forma ser remetido a esse ponto específico, seja sumário, seção, nota de rodapé, figura, tabela, anexo, apêndice, dentre outros elementos relevantes na formatação do trabalho. Os comandos apresentados pelo autor são: Vabel\{\}, \ref\{\} e \ageref\{\}, que permitem substituir, por exemplo, o "ver ANEXO A" por uma numeração crescente ou por um hyperlink que remeterá diretamente ao anexo indicado.

Para cruzar remissivas de equações dentro do texto, define-se, primeiramente, o rótulo e o nome que será atribuído à equação em todo o documento: Vabel\{eq:rotulodaequacao\}. Definido o rótulo da equação, que deve ser inserido desconsiderando os acentos gráficos, o autor digitará o comando que permite o cruzamento com o rótulo para que a remissiva seja gerada, mediante a estrutura: \ref\{eq:rotulodaequacao\}. Assim, na estrutura textual, o link é ativado, numa numeração crescente, para que, com um clique, o leitor seja conduzido à equação à qual o autor se referiu. Para remeter à página, em vez de remeter ao número da equação no texto, o comando será: pageref\{eq:rotulodaequacao\}. Essa mesma lógica de referências cruzadas vale para as remissivas de seções (Vabel\{sec:titulodasecao\}), figuras (Vabel\{fig:rotulodafigura\}), tabelas (Vabel\{tab:rotulodatabela\}), dentre outros elementos, inserindo-se os respectivos comandos: $\backslash r e f\{\}$ ou $\backslash$ pageref \{\} .

Para Fenn (2006, p. 3), a filosofia do LaTeX é centrar todos os esforços no conteúdo do documento, ou seja, por meio da edição do texto, enquanto que a parte de normalização, ou formatação conforme chamam alguns usuários, fica condicionada aos pacotes instalados na máquina. Um desses pacotes que permite com que os editores de LaTeX incorporem determinadas funcionalidades na produção do trabalho é o ABNTeX2, que tem sido aprimorado desde 2012 e que foi desenvolvido tendo como base a estrutura da versão pioneira do ABNTeX, desenvolvida entre os anos de 2001 e 2002 (LOPEZ; SILVA, 2013, p. 72-73). Foi esse pacote que embasou o template a ser apresentado neste estudo. Também merecem destaque as ferramentas que exportam referências em LaTeX, como é o caso do BibTeX (formato para gerar referências) e do JabRef (gerenciador de referências).

Antes, a lista de referências era composta apenas ao término do trabalho, fazendo com que o autor retornasse ao longo do texto para compilar tudo o que foi citado ou mesmo elencasse, às vezes de forma caótica, a bibliografia à qual recorreu (FENN, 2006). Hoje, devido 
aos vários recursos tecnológicos existentes, a lista de referências, assim como a lista de figuras, tabelas, gráficos etc., pode ser composta ao mesmo tempo em que o autor edita o seu texto, e um dos recursos que possibilita isso é o $B i b T e X$, que, na edição em $L a T e X$, permite ao pesquisador estruturar as suas referências nessa linguagem de programação, seja para uso imediato, seja para uso posterior. "O BibTeX é, basicamente, uma ferramenta [um formato] para automatizar sua lista de referências. Contudo, talvez você argumente que nem tudo que pode ser automatizado, deva ser automatizado". (FENN, 2006, p. 2, tradução nossa, grifo do autor). Talvez esse também seja o argumento de uma parcela de bibliotecários que resiste ao uso dos construtores e gerenciadores de referências, além, obviamente, da complexidade de utilizá-los.

O BibTeX traz uma linguagem de marcação (markup language) para compor a bibliografia do trabalho, por meio de uma base de dados externa que contém apenas dados bibliográficos, e essa é a primeira etapa que divide o conteúdo do texto do seu estilo bibliográfico. $\mathrm{O}$ arquivo de estilo é carregado externamente numa extensão denominada “.bib”, e, assim, o estilo bibliográfico determina a maneira como as citações e as referências serão formatadas no documento (FENN, 2006, p. 3-4). Desse modo, comprovamos que uma das vantagens do BibTeX para os pesquisadores das Ciências Exatas e de áreas afins é justamente estruturar um banco de dados bibliográficos armazenados permanentemente, que podem ser gerenciados por softwares específicos.

Os softwares gerenciadores de referências dispõem de diversas funcionalidades, dentre recolhimento, arquivamento e organização das referências bibliográficas ao longo do tempo, isto é, uma espécie de banco de dados de referências. Contêm vários estilos bibliográficos, além da integração com editores de texto. Nesse sentido, o JabRef pode ser caracterizado como um gerenciador de referências em LaTeX, com as funcionalidades de pacote adicional ou de software instalado no computador. Sua interface de entrada de dados é simples, conforme a figura 2, com os campos a serem preenchidos e posteriormente salvos em arquivo com extensão “.bib”, a mesma que permite com que os dados bibliográficos sejam exportados no formato BibTeX. 


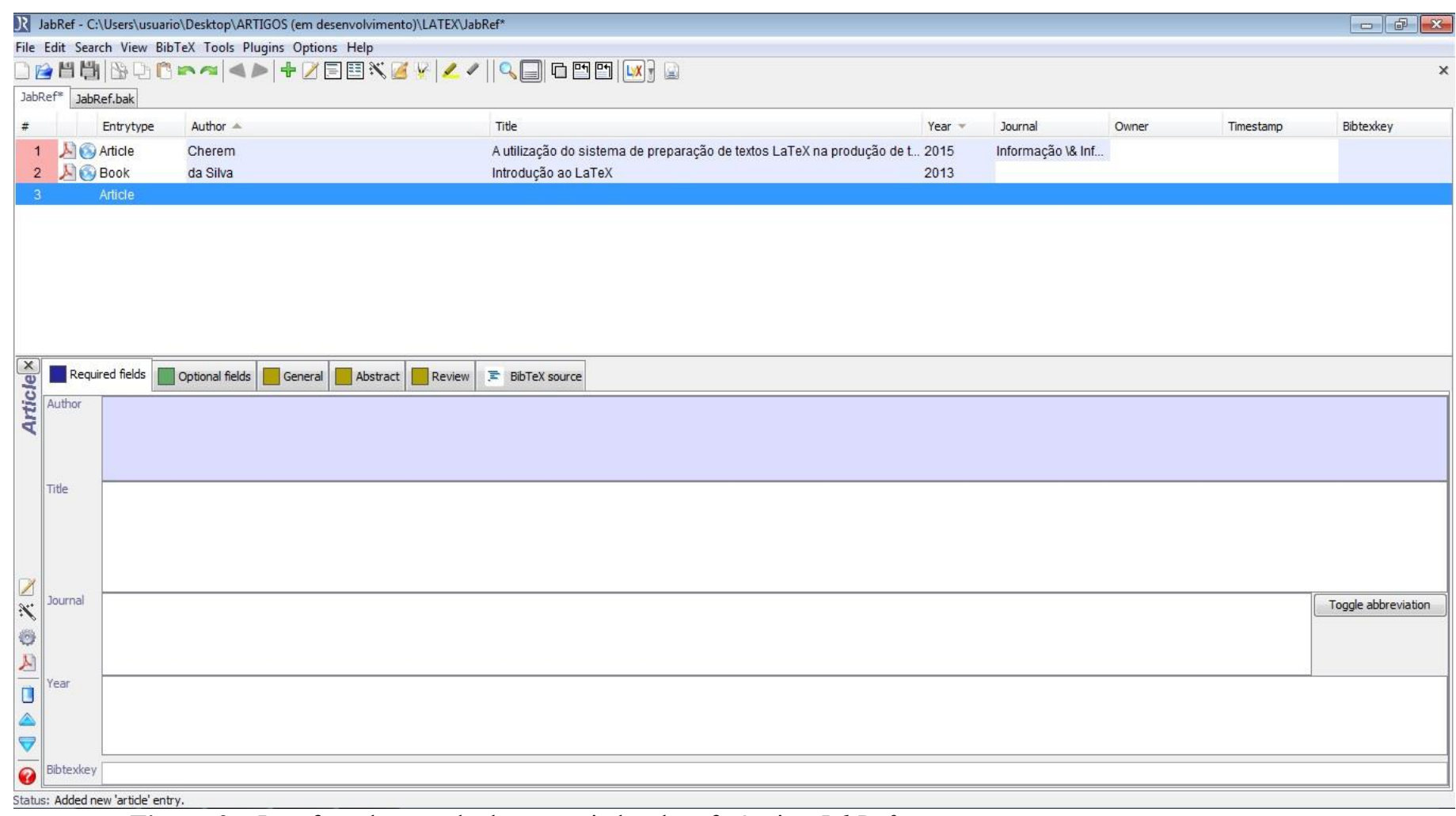

Figura 2 - Interface de entrada do gerenciador de referências JabRef.

Fonte: JabRef.

Vale ressaltar que outros construtores e gerenciadores de referências ${ }^{3}$, tais como o Cite this for me, EndNote, Mendeley e Zotero, por exemplo, assim como as ferramentas de exportação de diversas bases de dados e periódicos científicos, exportam em BibTeX as entradas que geram as referências de artigos e de outros tipos de publicações. Na figura 3, temos um exemplo de entrada no formato BibTeX, que irá gerar a referência em LaTeX na composição do trabalho e que está armazenada no banco de dados bibliográficos:

\footnotetext{
${ }^{3}$ Consideramos importante diferenciar os construtores de referência (citation builders ou citation makers) dos gerenciadores de referências bibliográficas (reference managers). Os citation builders ou citation makers são ferramentas livres disponíveis na Internet, que permitem a criação automática, individual ou em lista de referências bibliográficas segundo um estilo bibliográfico definido. Distinguem-se dos softwares para gestão de referências bibliográficas (EndNote, JabRef, Mendeley e Zotero, por exemplo) pelo caráter rápido com que as referências bibliográficas são geradas e prontas para aplicar (copiar e colar). Apesar dessa diferença básica, há diversos construtores de referência híbridos, isto é, que apresentam novos recursos que se assemelham aos gerenciadores de referências.
} 


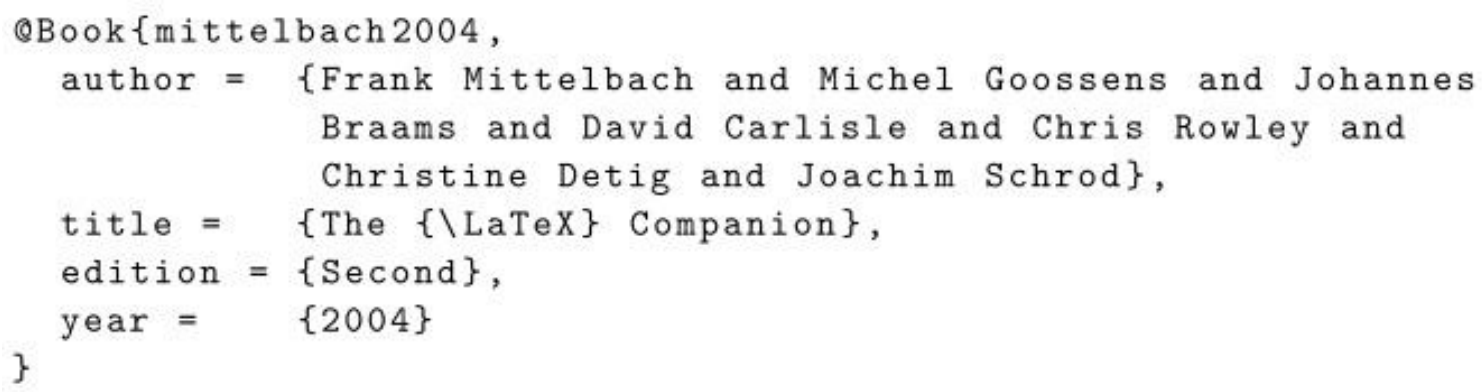

Figura 3 - Entrada para referência bibliográfica no formato $\mathrm{BibTeX}^{4}$.

Fonte: Fenn (2006, p. 5).

As entradas são as informações acerca da publicação utilizada na composição do texto, e que será referenciada a partir do BibTeX. São equivalentes aos elementos essenciais e complementares definidos pela NBR 6023 (ASSOCIAÇÃO BRASILEIRA DE NORMAS TÉCNICAS, 2002b) e variam de acordo com o tipo (ou classe, na linguagem do LaTeX) de documento. No exemplo acima, a classe de documento é livro, sinalizada pelo comando @Book, onde “mittelbach2004” é o rótulo utilizado para mencionar essa citação no texto. Fica a critério do usuário utilizar o rótulo que quiser. Normalmente, recomenda-se utilizar o último sobrenome do autor e o ano de publicação da obra.

Portanto, o BibTeX é o formato de exportação e de compilação das referências a partir de sites, softwares, editores de LaTeX ou dos gerenciadores de referências. Sobre esse aspecto, Garcia (2007, p. 2) diferencia estilo de citação e estilo para o formato de entrada nas referências ${ }^{5}$, duas coisas independentes, mas que se complementam. De acordo com o autor, o LaTeX é constituído por três estilos de citação considerados como sendo os principais: brackets, footnote e parentheses.

O estilo de citação em brackets é utilizado, basicamente, como remissiva no corpo do texto, seja para uma referência ou para alguma parte da publicação, como seção, figura, tabela, anexo etc. Observando as teses e dissertações da área de Física, constatamos que esse estilo de citação foi o mais utilizado pelos autores, e que corresponde ao sistema numérico exemplificado pela NBR 10520 (ASSOCIAÇÃO BRASILEIRA DE NORMAS TÉCNICAS, 2002a), conforme ilustrado na figura 4 :

\footnotetext{
${ }^{4}$ Há mais exemplos de entrada no formato BibTeX disponíveis em: 〈https://verbosus.com/bibtex-styleexamples.html>. Acesso em: 23 jul. 2017.

${ }^{5} \mathrm{O}$ formato BibTeX permite gerar referências segundo os estilos bibliográficos próprios do LaTeX. Os principais formatos e estilos estão disponíveis em: 〈http://www.cs.stir.ac.uk/ kjt/software/latex/showbst.html〉 e em: $\langle$ https://pt.sharelatex.com/learn/Bibtex_bibliography_styles〉. Acesso em: 23 jul. 2017.
} 


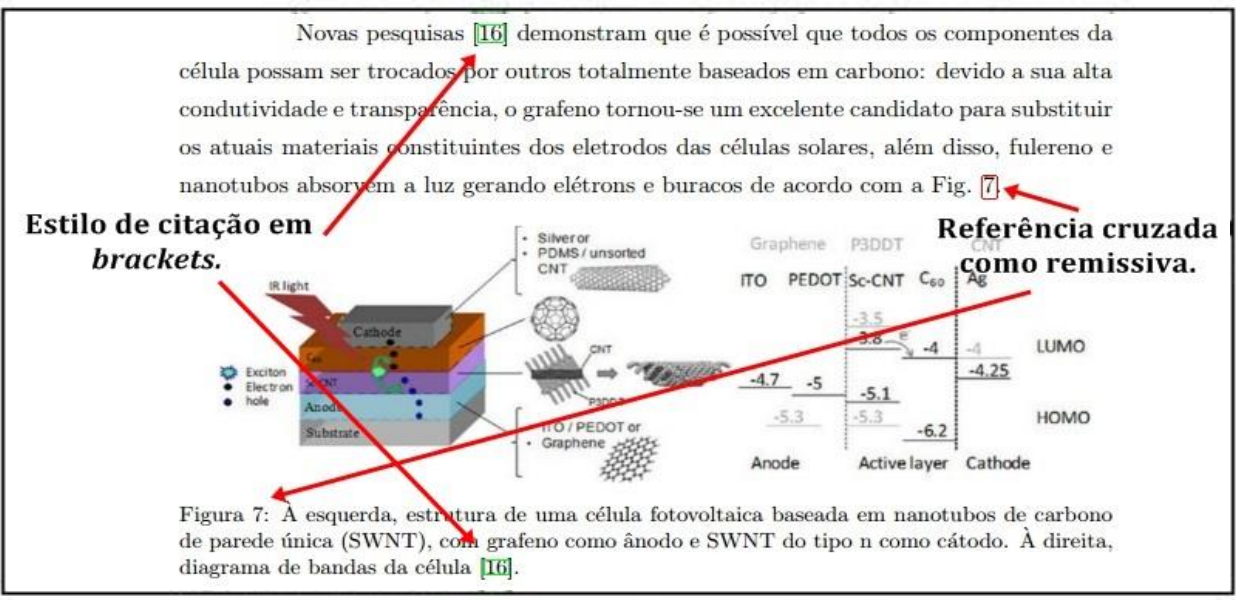

[10] K. S. Kim, Y. Zhao, H. Jang, S. Y. Lee, J. M. Kim, K. S. Kim, J. Ahn, P. Kim, J. Choi and B. H. Hong. Nature 457, $706(2009)$.

[11] Y. Hu, M. Ruan, Z. Guo, R. Dong, J. Palmer, J. Hankinson, C. Berger, and W. A. de Heer. J. Phys. D: Appl. Phys. 45, 154010 (2012).

[12] A. K. Geim. Science 324, 1530 (2009).

[13] A. K. Geim, and K. S. Novoselov. Nat. Mater. 6, 183 (2007).

[14] C. Lee, X. Wei, J. W. Kysar,and J. Hone. Science 321, 385 (2008).

[15] Y. M. Lin, C. Dimitrakopoulos, K. A. Jenkins, D. B. Farmer, H. Y. Chiu, A. Grill, Referência cruzada a fino final do trabalho.

$\rightarrow[16]$ M. P. Ramuz, M. Vosgueritchian, P. Wei, C. Wang. Y. Gao, Y. Wu, Y. Chen, and Z. Bao. ACS Nano 6 (11), 10384 (2012).

Figura 4 - Estilo de citação em brackets e referências cruzadas. Fonte: Adaptado de Cavalcante (2016, p. 18).

O comando utilizado para as citações é o \cite. De acordo com Fenn (2006, p. 8), o LaTeX foi estruturado com base num esquema numérico default desenvolvido especificamente para se assemelhar ao estilo bibliográfico disponível num programa chamado Scribe, que foi bastante popular na escrita científica à época de Leslie Lamport. Esse estilo é usado principalmente nas áreas da Matemática, Ciências da Computação e Ciências da Natureza. "Se quisermos utilizar um estilo bibliográfico diferente do numérico, devemos carregar pacotes adicionais externos" (FENN, 2006, p. 8, tradução nossa).

Garcia (2007) apresenta os estilos de citação autor-data (footnotes e parentheses), fazendo um contraponto com o estilo de citação anterior, ao explicar que o estilo em brackets é insuficiente no caso da necessidade de mencionar a fonte (o autor, o estudo ou o documento em que se embasou). Nesse caso, os estilos autor-data, equivalentes ao sistema autor-data da $\mathrm{ABNT}$, são os mais indicados a serem adotados no texto. $\mathrm{O}$ autor discorre, ainda, acerca do padrão e dos comandos desses estilos em instituições como Harvard e Chicago, além de suas vantagens e desvantagens (GARCIA, 2007, p. 5-8). Dentre as vantagens, destacamos a mais 
importante: a de tornar automáticas as remissivas e as referências cruzadas, onde Garcia (2007, p. 8) corrobora que os usuários do Microsoft Word nem sempre estão cientes de que esse processo pode ser automatizado, o que torna, segundo o autor, sem sentido os computadores e, em particular, o $\mathrm{TeX}$ oferecerem esses recursos.

Até então, as normas da ABNT ainda não abordam a incorporação de hyperlinks às citações $^{6}$, o que é permitido pelos estilos em LaTeX e defendido por Garcia (2007, p. 8, tradução nossa): "De fato, é um pouco irônico que o desenvolvimento acelerado da preparação de documentos eletrônicos faça com que essa vantagem [da automatização das remissivas e das referências cruzadas, conforme citado no parágrafo anterior] dos estilos autor-data se torne uma dificuldade [...]" No entanto, discordamos do autor nessa afirmação, pois a atividade mediadora do bibliotecário pode ser a solução para isso, no sentido de apresentar ao usuário as funcionalidades e os recursos do LaTeX.

Um dos pacotes mencionados por Fenn (2006, p. 8) que vai ao encontro do estilo de citação footnote é o jurabib, recomendado para notas de rodapé e abreviações de títulos de periódicos. No entanto, o autor chama a atenção para o pacote natbib, intrínseco ao esquema autor-data sugerido pelo estilo bibliográfico das normas de Chicago. Segundo Fenn (2006, p. 8), o pacote foi desenvolvido originalmente para as Ciências da Natureza, mas tem sido popular em muitas áreas, dentre elas, a Linguística. Garcia (2007, p. 6-7) traz exemplos de alguns dos comandos do natbib. A figura 5 ilustra esses exemplos com base no comando lcite e na visualização do texto em seu formato de saída:

\footnotetext{
${ }^{6}$ Apesar de que a NBR 6027 (sumário) já apresenta um tópico sobre esse aspecto (ASSOCIAÇÃO BRASILEIRA DE NORMAS TÉCNICAS, 2012, p. 3, seção 5.7).
} 


\begin{aligned} & \hline (citep[notably][]) $\begin{array}{l}\text { Some philosophers of science have claimed that science pro- } \\ \text { gresses as life (notably Kuhn 1996; Koestler 1959). Kuhn started } \\ \text { his conceptual trip with his exploration of the Copernican Rev- }\end{array} \\ & \begin{array}{c}\backslash \text { citeyearpar } \\ \text { olution (1957). At virtually the same time, at the other side of } \\ \text { the Atlantic, the same trip was documented in Koestler (1959). } \\ \text { In musicology, Leo Treitler expresses very similar views (1984, } \\ \text { 1989, 1999). Kuhn's 'paradigms' were directly addressed by } \\ \text { musicians since 1991 (McClary). } \\ \text { There was and is, of course, opposition to Kuhn, whose } \\ \text { ideas were always shunned by mainstream philosophy of sci- } \\ \text { ence. Most virulent of all was the criticism by Imre Lakatos } \\ \text { (1970). In musicology, this criticism has no direct offspring, } \\ \text { but the other extreme, the 'anarchy of knowledge' (Feyerabend }\end{array} \\ & \begin{array}{l}\text { 1978), finds parallels in the diverse manifestos of postmod- } \\ \text { ernist musicology, for example Tomlinson's (1984). }\end{array} \\ &$ Tomlinson's $\backslash$ citeyearpar \end{aligned}

Figura 5 - Estilo de citação autor-data por meio do pacote natbib.

Fonte: Garcia (2007, p. 7).

Dentre os comandos mostrados na figura 5, temos: \citeyear (que isola o ano da publicação entre parênteses); \citet (equivalente à menção da fonte no início do parágrafo de acordo com as normas da ABNT); e \citep (equivalente à menção da fonte no final do parágrafo de acordo com as normas da ABNT).

Em sites especializados, tais como o do ShareLaTeX, são disponibilizados templates para publicações em forma de livros, teses, dissertações, artigos científicos, dentre outros formatos, com modelos predefinidos de acordo com a necessidade do usuário. Os modelos variam conforme as universidades e periódicos científicos. No caso dos templates, o autor apenas irá incluir o conteúdo seguindo o modelo disponibilizado, e é justamente com o conteúdo, de forma lógica e codificada, que ele deverá se preocupar no uso do LaTeX. Já os bibliotecários poderão explorar os recursos referentes à normalização e estruturação do documento, seja com a finalidade de aperfeiçoar ou complementar os templates, seja explorando-os em treinamentos e capacitações dos usuários das bibliotecas.

Levando em consideração que o desenvolvimento de trabalhos acadêmicos em formato digital tem por finalidade a produção de documentos eletrônicos, nada mais sensato do que proporcionar ao leitor uma diversidade de recursos que o permitam navegar pela estrutura e pelo conteúdo do documento apresentado na tela do computador, normalmente em PDF. Nessa vertente, as funcionalidades do $\operatorname{LaTeX}$ permitem que a estruturação do documento atinja essa demanda em potencial. No caso do uso de remissivas no decorrer do texto, por exemplo, mais especificamente quando o autor chama a atenção do leitor num determinado parágrafo para que 
ele veja mais detalhes sobre o assunto numa seção distante da que está fazendo a leitura, há um comando no $L a T e X$ que possibilita a fixação da remissiva. Sabendo disso, o bibliotecário poderá orientar o usuário, apresentando a variedade de recursos que caracterizam o LaTeX.

Nesse sentido, um aspecto importante está relacionado, como vimos, à citação e às referências. Recursos como o BibTeX são amplamente usados em associação com o LaTeX. Esse tipo de associação é o que permite que modelos de referência de documentos sejam importados para o $\operatorname{LaTeX}$, fornecendo, assim, uma sintaxe básica, ou seja, uma estrutura, um modelo que, ao ser preenchido ou ter seu conteúdo substituído, origina as referências dos trabalhos citados. Esses modelos estão disponíveis em sites e gerenciadores para os mais variados padrões de referência. Ajudar a manter tais modelos atualizados, em repositórios como o GitHub e o CSL (Citation Style Language), por exemplo, pode, inclusive, constituir-se numa das contribuições dos bibliotecários para a comunidade que utiliza o LaTeX.

No que se refere à proposta de template estruturado no ShareLaTeX $X^{7}$, e à consequente elaboração deste artigo, contamos com a parceria de dois discentes que participaram de um dos treinamentos de normalização de trabalhos acadêmicos. A plataforma ShareLaTeX consiste num editor de LaTeX online, incorporado ao Overleaf, que permite o compartilhamento gratuito (entre duas pessoas) do trabalho em edição. A plataforma pode ser acessada de qualquer navegador e em dispositivos móveis, e não há necessidade de instalação de programas ou de pacotes adicionais. Para acessá-la, basta cadastrar e-mail e senha.

Ao criar o arquivo que dará origem à lista de referências, o bibliotecário precisa estar atento a alguns detalhes, como utilizar a extensão ".bib” ao nomear o arquivo, pois é essa extensão que garantirá que o $L a T e X$ reconheça esse arquivo como sendo a lista de bibliografias e estabeleça, após a compilação, as necessárias relações entre as citações e suas respectivas referências. Ainda sobre a elaboração da lista de referências, é importante que, durante o processo de construção da mesma, seja atribuído um rótulo ao lado do nome de cada um dos modelos de referência inseridos. Essa atribuição torna mais simples a vinculação das citações à referência, uma vez que bastará inserir o comando lcite\{nomedafonte\} próximo ao texto da citação e compilar o documento para que os dados do autor e da obra citada sejam inseridos no arquivo de acordo com o formato definido.

\footnotetext{
${ }^{7}$ Template disponível em: 〈http://www.sharelatex.com/project/57740f53c4b5936215e82746>. Acesso em: 24 jul. 2017.
}

InCID: R. Ci. Inf. e Doc., Ribeirão Preto, v. 9, n. 1, p. 25-51, mar./ago. 2018. 
A escolha do estilo bibliográfico da lista de referências é outro aspecto fundamental. É por meio dessa escolha que a sintaxe básica importada e o conteúdo a ela acrescentado aparecerão no formato correto depois de concluído o trabalho. Para indicar o estilo adotado na lista de referências, inserimos, no local onde a lista de referências ficará localizada, o comando |bibliographystyle\{nomedoestilo\} e, abaixo dele, o comando |bibliography\{nomedoarquivoquearmazenaabibliografia\}. A partir da interpretação desses comandos, o LaTeX irá processar que o conteúdo do arquivo da bibliografia deve ser inserido no trabalho com o estilo identificado. No caso do template que embasou esta pesquisa, o estilo predefinido foi o da ABNT, cuja estrutura pode ser visualizada na figura 6 :
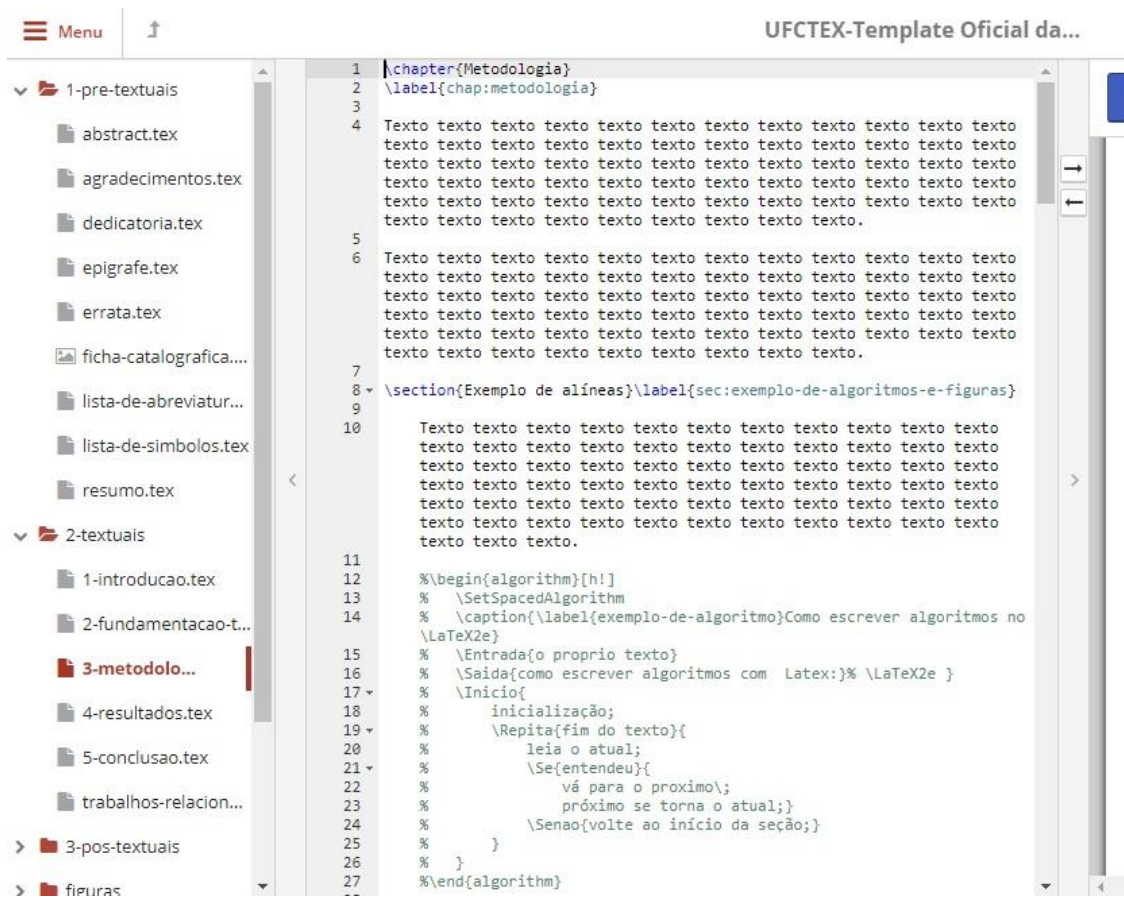

$\widehat{S A b}$ Revisar כ Histórico

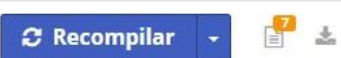
3 METODOLOGIL

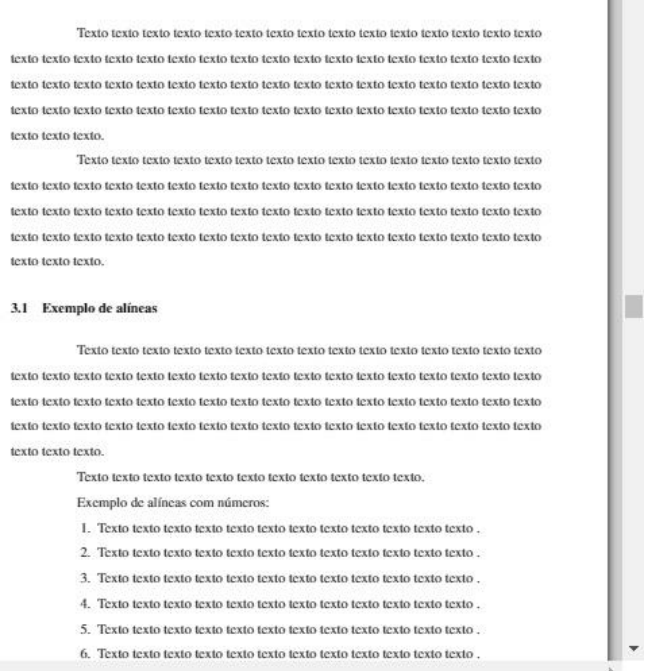

Figura 6 - Template estruturado no ShareLaTeX. Fonte: ShareLaTeX. 2016

Conforme a figura acima, mais especificamente na coluna da esquerda, cada elemento do trabalho acadêmico consta em pastas devidamente nomeadas, que contêm os códigos-fonte utilizados na estruturação do template. Ao centro, é possível fazer a edição do documento, de acordo com os comandos da linguagem $\operatorname{LaTeX}$, e ao lado direito visualiza-se o formato de saída do arquivo (PDF). As orientações gerais para o usuário, visando à formatação e normalização de trabalhos acadêmicos, foram dispostas numa pasta denominada documento.tex.

A figura 7 (a seguir) apresenta o código principal do template aplicado neste trabalho. Em \documentclass foram atribuídas as opções de tamanho da página A4, fonte tamanho 12, 
seção primária em caixa alta, seções secundárias e terciárias com primeira letra em caixa alta e impressão em apenas uma face do papel. Também estão habilitados os corretores ortográficos em inglês, espanhol e português (Brasil). As equações estão configuradas para ficarem alinhadas à esquerda. Outras opções estão em outro arquivo chamado preambulo. Esse arquivo é inserido pelo comando \input\{lib/preambulo\}. Nesse arquivo estão listados os packages, ou pacotes, que contêm códigos de configurações que permitem diferentes variações gráficas, tais como inserir figuras, tabelas, fórmulas químicas, letras gregas e, o mais importante, o estilo bibliográfico adotado pela instituição, que neste caso é o ufctex, criado especificamente para atender às normas da ABNT.
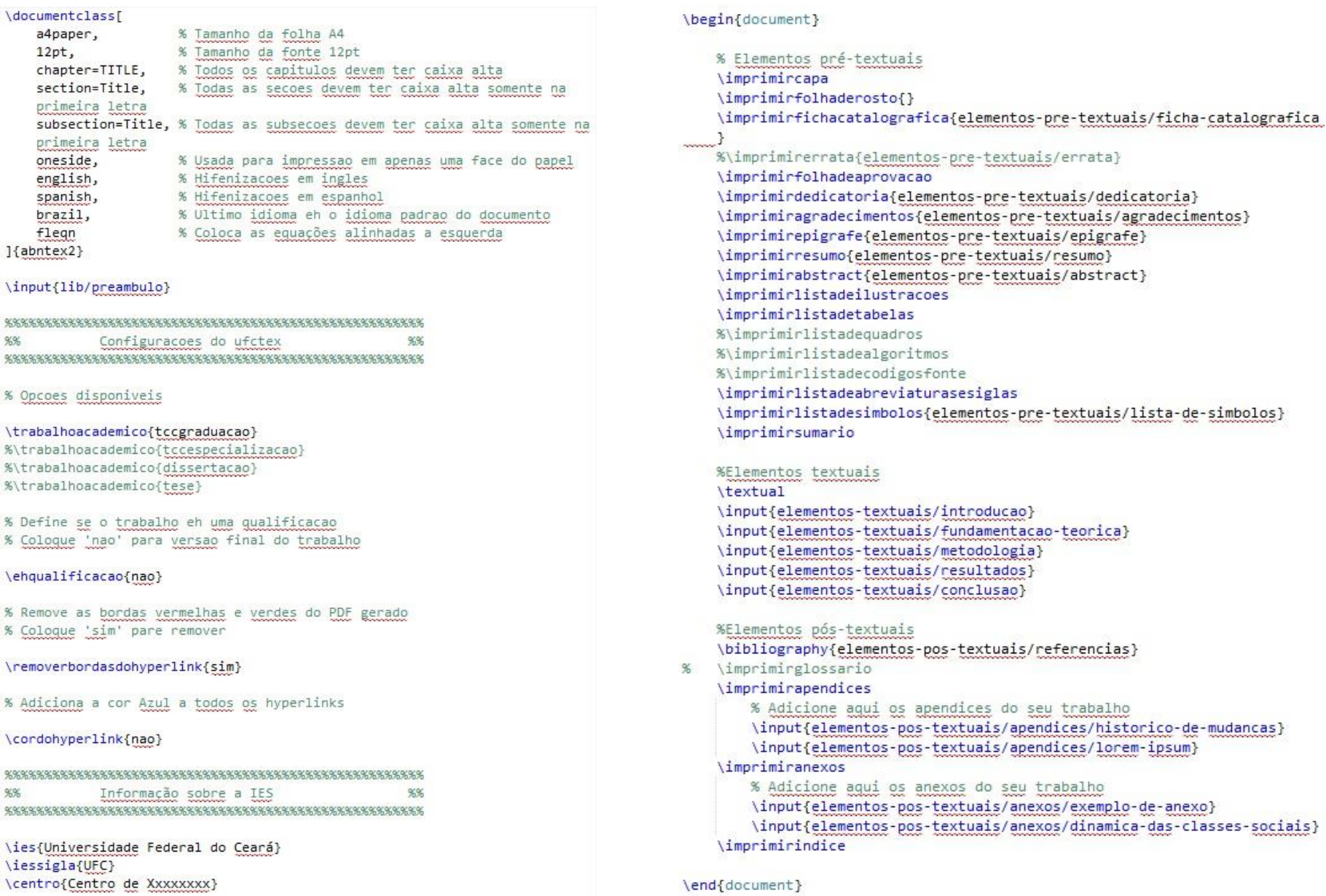

Figura 7 - Orientações gerais para normalização no template estruturado no ShareLaTeX.

Fonte: ShareLaTeX. 2016.

Em "Configurações do ufctex" (lado esquerdo da figura 7), o autor poderá escolher a opção correspondente ao trabalho que está desenvolvendo, ou seja, trabalho de conclusão de curso de graduação, especialização, dissertação ou tese. Essas opções diferenciam-se entre si apenas para a criação de uma macro nos pré-textuais, pois a formatação textual e pós-textual é 
a mesma para todos esses trabalhos acadêmicos. O autor terá, ainda, a opção de ajustar seu trabalho para um exame de qualificação e de remover a cor dos links que forem utilizados. Em "Informações sobre a IES", o autor entrará com as informações da Instituição de Ensino Superior. O nome e a sigla da instituição é, por padrão, UFC. O autor entrará com o centro, departamento e o curso que faz na universidade.

A coluna direita da figura 7 mostra onde o autor escolherá os elementos pré-textuais, textuais e pós-textuais que serão impressos. Por padrão, os elementos pré-textuais são: capa, folha de rosto, ficha catalográfica, folha de aprovação, dedicatória, agradecimentos, epígrafe, resumo, resumo em língua estrangeira, lista de ilustrações, lista de abreviaturas, lista de símbolos e sumário. Alguns desses elementos são opcionais e alguns autores podem optar por não utilizar determinado elemento, como a epígrafe, por exemplo. Caso o autor não queira imprimir um elemento, basta acrescentar o símbolo "\%" na frente do mesmo.

Os elementos textuais padrão no template são: introdução, fundamentação teórica, metodologia, resultados e conclusão. Outra estrutura de trabalho pode ser adotada pelos autores, conforme a orientação de seus professores. Já os elementos pós-textuais são: referências, apêndices, anexos e índice remissivo, sendo que estes três últimos são opcionais e podem ser suprimidos com símbolo de percentual. O entendimento desses recursos, bem como dos que foram apresentados no decorrer deste trabalho, e do modo como eles são utilizados podem fazer com que o bibliotecário atue de forma mais efetiva no serviço de referência ao se deparar com uma demanda de orientação à normalização de trabalhos acadêmicos utilizando o LaTeX. 


\section{Considerações finais}

Em treinamentos de normalização ou durante a apresentação dos serviços da biblioteca, deparamo-nos com dúvidas de diferentes tipos sobre a normalização de trabalhos acadêmicos, entre elas, questionamentos e informações a respeito de programas ou ferramentas para utilização nos editores de texto, livres ou proprietários, gerenciadores de referências e também sobre o LaTeX. Ou seja, os usuários sempre levantam questões acerca do assunto, exigindo do bibliotecário a preparação para atenuar as dúvidas suscitadas.

Embora haja templates disponíveis para a comunidade universitária, entendemos que o primeiro passo para o bibliotecário compreender o LaTeX é estruturar um template desde a sua etapa inicial, principalmente para entender como a linguagem funciona e quais os recursos que podem ser explorados no âmbito da editoração e normalização de trabalhos acadêmicos. Obviamente, não pretendemos defender neste artigo o conhecimento da complexidade do LaTeX, mas sim dos recursos de que ele dispõe e que vão diretamente ao encontro da normalização, tais como paginação, definição das margens do documento, sumário, citações, referências etc.

Consideramos as ferramentas e funcionalidades do $\mathrm{LaTeX}$ como sendo parâmetros para a atividade de normalização de trabalhos acadêmicos. Há uma grande probabilidade, com base na elaboração deste artigo, de que a produção de documentos em formato eletrônico gere demanda em potencial que fará com que as funcionalidades do LaTeX sejam bastante disseminadas em bibliotecas universitárias. É preciso, então, que os bibliotecários estejam atentos às mudanças e melhorias que ocorrem nas ferramentas destinadas à produção e normalização de textos técnico-científicos.

Mencionamos, nesse sentido, não apenas a linguagem $L a T e X$, mas também a integração com gerenciadores de referências, a alimentação de repositórios de citações, a colaboração ao estruturar ou adequar templates, dentre outras possibilidades. No caso do ShareLaTeX, com o qual trabalhamos diretamente, manter-se-á uma avaliação contínua de seu uso pela comunidade universitária, adequando-o conforme o feedback recebido a partir das estatísticas de acesso e uso do template disponibilizado no site da biblioteca, bem como das observações e dúvidas enviadas pelos próprios usuários. A sua integração à plataforma Overleaf também será um fator a ser considerado.

Uma das intenções na produção deste artigo é fazer com que bibliotecários, pesquisadores em Ciência da Informação e estudantes de Biblioteconomia se sintam motivados 
a explorar o LaTeX de modo a conhecer os recursos e as ferramentas utilizadas pela comunidade usuária de bibliotecas universitárias, mais especificamente das Ciências Exatas e de áreas afins, o que não impede a extensão do uso do LaTeX às demais áreas do conhecimento. Há, inclusive, a possibilidade de adequar templates para periódicos científicos em Biblioteconomia e Ciência da Informação, o que será de grande vantagem quando equações, fórmulas ou cálculos complexos forem utilizados no texto.

Mesmo com a complexidade da linguagem de programação envolvida na estrutura do LaTeX, salientamos que o bibliotecário precisa estar inserido no uso dessa ferramenta, inclusive ministrando treinamentos sobre as suas funcionalidades. Dessa forma, os bibliotecários têm plenas condições de se tornarem parceiros de professores, estudantes e monitores que dominam o LaTeX, contribuindo para com a educação de usuários tanto no uso desse recurso quanto na sensibilização da comunidade universitária acerca da importância da normalização de trabalhos acadêmicos.

\section{Referências}

\section{AMERICAN PSYCHOLOGICAL ASSOCIATION. Manual de Publicação da APA.} Tradução: Daniel Bueno. 6. ed. Porto Alegre: Penso, 2012.

APPOLINÁRIO, Fábio. Dicionário de metodologia científica: um guia para a produção do conhecimento científico. São Paulo: Atlas, 2009.

ARAUJO, Lauro César. A classe abntex2: documentos técnicos e científicos brasileiros compatíveis com as normas [da] ABNT. [Manual atualizado em] 26 de fevereiro de 2016a. Disponível em: <http://mirrors.rit.edu/CTAN/macros/latex/contrib/abntex2/doc/abntex2.pdf $>$. Acesso em: 03 mar. 2016.

ARAUJO, Lauro César. O pacote abntex2cite: estilos bibliográficos compatíveis com a ABNT NBR 6023. [Manual atualizado em] 26 de fevereiro de 2016b. Disponível em: <http://ctan.sharelatex.com/tex-archive/macros/latex/contrib/abntex2/doc/abntex2cite.pdf $>$. Acesso em: 03 mar. 2016.

ARAUJO, Lauro César. O pacote abntex2cite: tópicos específicos da ABNT NBR 10520:2002 e o estilo bibliográfico alfabético (sistema autor-data). [Manual atualizado em] 26 de fevereiro de 2016c. Disponível em:

$<$ http://mirror.hmc.edu/ctan/macros/latex/contrib/abntex2/doc/abntex2cite-alf.pdf $>$. Acesso em: 03 mar. 2016.

ASSOCIAÇÃO BRASILEIRA DE NORMAS TÉCNICAS. NBR 10520: informação e documentação: citações em documentos: apresentação. Rio de Janeiro, 2002a. 
ASSOCIAÇÃO BRASILEIRA DE NORMAS TÉCNICAS. NBR 6023: informação e documentação: referências: elaboração. Rio de Janeiro, $2002 b$.

ASSOCIAÇÃO BRASILEIRA DE NORMAS TÉCNICAS. NBR 6027: informação e documentação: sumário: apresentação. Rio de Janeiro, 2012.

CAVALCANTE, Lucas Samir Ramalho. Estados snake e filtros de vale baseados somente em tensão mecânica em monocamadas de grafeno. 2016. 63 f. Dissertação (Mestrado em Física) - Programa de Pós-Graduação em Física, Centro de Ciências, Universidade Federal do Ceará, Fortaleza, 2016. Disponível em: 〈http://www.repositorio.ufc.br/handle/riufc/16263〉. Acesso em: 23 jul. 2017.

CHEREM, Youssef Alvarenga. A utilização do sistema de preparação de textos LaTeX na produção de textos acadêmicos no Brasil: uma investigação preliminar e perspectivas.

Informação \& Informação, Londrina, v. 20, n. 1, p. 228-249, jan./abr. 2015. Disponível em: <http://www.uel.br/revistas/uel/index.php/informacao/article/viewFile/18495/pdf_52>. Acesso em: 03 mar. 2016. DOI: 10.5433/1981-8920.2015v20n1p228.

CLARK, Malcolm. A plain TEX primer. Oxford: Oxford University Press, 1992.

ELLIOT, Jhon. La investigación-acción en educación. Tradução: Pablo Manzano. 4. ed. Madrid: Morata, 2000.

FENN, Jürgen. Managing citations and your bibliography with BibTeX. The PracTeX Journal, n. 4, 2006. Disponível em: 〈https://tug.org/pracjourn/2006-4/fenn/fenn.pdf >. Acesso em: 05 mar. 2017.

GARCIA, Federico. LaTeX and the different bibliography styles. The PracTeX Journal, n. 2, 2007. Disponível em: 〈https://tug.org/pracjourn/2007-2/garcia/garcia.pdf >. Acesso em: 05 mar. 2017.

INTERNATIONAL COMMITTEE OF MEDICAL JOURNAL EDITORS. About ICMJE. Disponível em: <http://www.icmje.org/about-icmje>. Acesso em: 23 jul. 2017.

KOTTWITZ, Stefan. LaTeX: beginner's guide. Birmingham: Packt Publishing, 2011. Livro eletrônico: Kindle e-reader.

LOPEZ, Ivo Fernandez; SILVA, Maria Darci Godinho da. Introdução ao uso do LaTeX. Rio de Janeiro, 2013. Disponível em:

<http://www.bookyards.com/en/member/page/ivolopez $>$. Acesso em: 26 fev. 2016.

MARTINS FILHO, Plinio. Manual de editoração e estilo. Campinas: Editora da Unicamp; São Paulo: Editora da Universidade de São Paulo; Belo Horizonte: Editora UFMG, 2016.

MITTELBACH, Frank et al. The LaTeX companion: tools and techniques for computer typesetting. 2nd ed. Boston: Pearson Education, 2004. Livro eletrônico: Kindle e-reader. 
NEVES, Antero. A minha experiência em LaTeX. The PracTeX Journal, n. 3, 2007. Disponível em: <https://tug.org/pracjourn/2007-3/neves/neves.pdf >. Acesso em: 05 mar. 2017.

OLIVEIRA, Rogério Amigo de. Informática: teorias e questões de concurso com gabarito. Rio de Janeiro: Elsevier, 2007.

SHARELATEX. UFCTEX: template oficial da Universidade Federal do Ceará. Fortaleza, 2016. Disponível em: 〈http://www.sharelatex.com/project/57740f53c4b5936215e82746>. Acesso em: 24 jul. 2017.

SILVA, Fabiano Couto Corrêa da. Bibliotecários especialistas: guia de especialidades e recursos informacionais. Brasília, DF: Thesaurus, 2005.

SOUTO, Gilberto. Curso de LaTeX. Florianópolis, [200-]. Disponível em: <http://www.uft.edu.br/engambiental/prof/catalunha/arquivos/latex/latex_GilbertoSouto.pdf $>$. Acesso em: 25 fev. 2016.

\section{Agradecimentos}

Aos discentes do Curso de Física da UFC: Anthônio Nunes Moreira Netto, Renan William Pereira de Castro e Thiago Alves de Moura. Aos professores coordenadores do Laboratório de Estatística e Matemática Aplicada da UFC: Prof. ${ }^{a}$ Sílvia Maria de Freitas e Prof. Ronald Targino Nojosa. Ao discente do Curso de Engenharia Elétrica da UFC: Alan Batista de Oliveira. 